\title{
Diminazene enhances stability of atherosclerotic plaques in ApoE-deficient mice
} \author{
Maiia E. Bragina ${ }^{\text {a }}$, François Mach ${ }^{\text {b }}$, Mohan K. Raizada ${ }^{d}$, Robson A.S. Santos ${ }^{\text {e }}$, \\ Rafaela F. da Silva ${ }^{\mathrm{e}}$, Nikolaos Stergiopulos ${ }^{\mathrm{a}}$ \\ a Institute of Bioengineering, Ecole Polytechnique Fédérale de Lausanne, Lausanne, Switzerland \\ b Division of Cardiology, Faculty of Medicine, Foundation for Medical Researches, University of Geneva, Geneva, Switzerland \\ c First Clinic of Internal Medicine, Department of Internal Medicine, University of Genoa School of Medicine, Genoa, Italy \\ ${ }^{d}$ Department of Physiology and Functional Genomics, College of Medicine, University of Florida, Gainesville, United States \\ e Department of Physiology and Biophysics, Federal University of Minas Gerais, Belo Horizonte, Brazil
}

Rodrigo A. Fraga-Silva ${ }^{\mathrm{a}, *}$, Fabrizio Montecucco ${ }^{\mathrm{b}, \mathrm{c}}$, Fabiana P. Costa-Fraga ${ }^{\mathrm{a}}$, Alessio Nencioni ${ }^{\mathrm{c}}$, Irene Caffa ${ }^{\mathrm{c}}$,

\section{A R T I C L E I N F O}

Article history:

Received 23 February 2015

Received in revised form 22 July 2015

Accepted 20 August 2015

Available online 22 August 2015

\section{Keywords:}

Diminazene

Angiotensin-converting enzyme 2

Angiotensin

Atherosclerosis

Inflammation

Plaque stability

Plaque vulnerable

\begin{abstract}
A B S T R A C T
Angiotensin (Ang) II contributes to the development of atherosclerosis, while Ang-(1-7) has atheroprotective actions. Accordingly, angiotensin-converting enzyme 2 (ACE2), which breaks-down Ang II and forms Ang-(1-7), has been suggested as a target against atherosclerosis. Here we investigated the actions of diminazene, a recently developed ACE2 activator compound, in a model of vulnerable atherosclerotic plaque. Atherosclerotic plaque formation was induced in the carotid artery of ApoE-deficient mice by a shear stress (SS) modifier device. The animals were treated with diminazene $(15 \mathrm{mg} / \mathrm{kg} / \mathrm{day})$ or vehicle. ACE2 was strongly expressed in the aortic root and low SS-induced carotid plaques, but poorly expressed in the oscillatory SS-induced carotid plaques. Diminazene treatment did not change the lesion size, but ameliorated the composition of aortic root and low SS-induced carotid plaques by increasing collagen content and decreasing both MMP-9 expression and macrophage infiltration. Interestingly, these beneficial effects were not observed in the oscillatory SS-induced plaque. Additionally, diminazene treatment decreased intraplaque ICAM-1 and VCAM-1 expression, circulating cytokine and chemokine levels and serum triglycerides. In summary, ACE2 was distinctively expressed in atherosclerotic plaques, which depends on the local pattern of shear stress. Moreover, diminazene treatment enhances the stability of atherosclerotic plaques.
\end{abstract}

(c) 2015 Elsevier Inc. All rights reserved.

\section{Introduction}

Vulnerable plaque, characterized by the presence of intense inflammation and a lipid-rich necrotic core covered by a thin fibrous cap, have a higher propensity to rupture and lead to subsequent thrombotic occlusion. Indeed, it is well recognized that the risk of thrombosis in atherosclerosis largely depends on plaque composition [1,2].

Local shear stress forces have been documented as a biomechanical factor which modulates atherogenesis and plaque composition [3-5]. For instance, it has been shown that local low shear stress (LSS) may induce plaque formation and a vulnerable composition [5]. Several molecular pathways are involved in the shear-stress inducing plaque vulnerability process; however, such mechanisms are poorly known.

\footnotetext{
* Corresponding author at: Laboratory of Hemodynamics and Cardiovascular Technology, Institute of Bioengineering, Ecole Polytechnique Fédérale de Lausanne, Station 17, BM 5115, CH-1015 Lausanne, Switzerland.

E-mail address: rodrigo.fragasilva@epfl.ch (R.A. Fraga-Silva).
}

The renin-angiotensin system (RAS), a major regulator of cardiovascular function, is highly involved in the genesis and progression of atherosclerosis [6-8]. Moreover, this system seems to actively influence the composition of atherosclerotic plaques. Angiotensin (Ang) II, the main effector of RAS, contributes to atherosclerosis development by increasing vascular permeability, inflammatory cell infiltration and LDL oxidation and uptake [9-11]. Moreover, Ang II may increase plaque vulnerability by modulating macrophage trapping, increasing reactive oxygen species production and weakening the fibrous cap by activation of matrix metalloproteinase (MMP) [10,12,13].

Contrarily to Ang II, emerging data indicates that Ang-(1-7), another effector of RAS, has atheroprotective actions [14-16]. It has been shown that Ang-(1-7) infusion promotes a reduction in plaque size and improves vascular endothelial function in hypercholesterolemic mice [17]. Moreover, long-term treatment with Ang-(1-7) enhances atherosclerotic plaque stability by increasing intraplaque collagen content, decreasing MMP-9 expression and reducing neutrophil and macrophage infiltration [18]. 
LSS

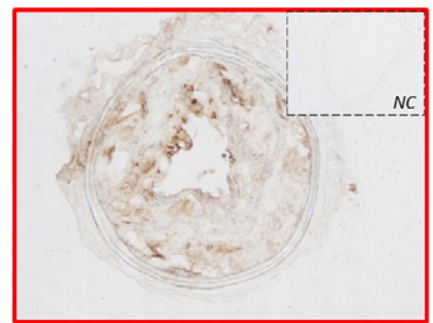

OSS

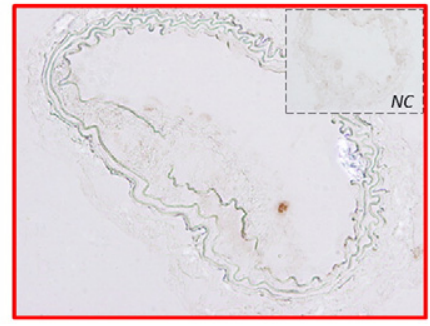

Aortic roots

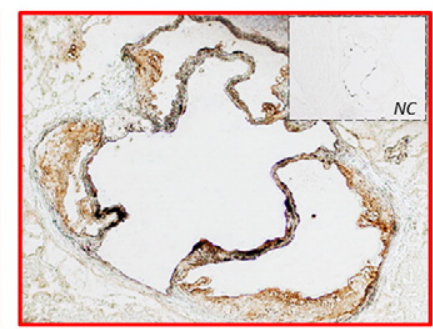

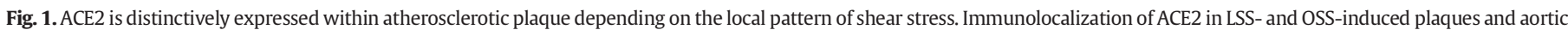

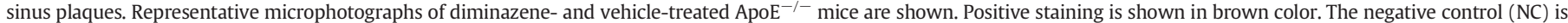
shown in the upper right panels. No difference in ACE2 expression was observed between treated or non-treated mice.

Angiotensin-converting enzyme 2 (ACE2) is a key regulator of Ang II and Ang-(1-7) levels. This enzyme breaks-down Ang II, by cleaving the C-terminal phenylalanine and, consequently, forms Ang-(1-7); therefore, ACE2 reduces Ang II and favors Ang-(1-7) actions [19]. ACE2 enzyme is expressed in animal models [20] and human [21] atherosclerotic plaques, playing a protective role in atherosclerosis [14]. Indeed, ACE2 overexpression attenuates the progression of atherosclerotic lesions and increases plaque stability [22]. Contrarily, ACE2 deficiency in low-density lipoprotein receptor $\left(\mathrm{Ldlr}^{-/-}\right)$or apolipoprotein $\mathrm{E}\left(\mathrm{ApoE}^{-1-}\right)$-deficient mice worsens atherogenesis [23-25]. Based on these observations, ACE2 has being suggested as a potential target for the treatment of atherosclerosis.

In the present study, an investigation on the effects of diminazene (a recently developed pharmacological ACE2 activator) [26,27], in a mouse model of vulnerable atherosclerotic plaque was performed.

\section{Methods}

\subsection{Experimental design}

The atherosclerotic plaques were induced within the right carotid artery of $\mathrm{ApoE}^{-/-}$mice by modifying the local pattern of shear stress
[5]. ApoE $\mathrm{E}^{-/-}$mice with a $\mathrm{C} 57 \mathrm{BL} / 6 \mathrm{~J}$ background $(\mathrm{n}=40)$ were obtained from Jackson Laboratories (Les Oncins, France). Animals at 15-20 weeks received western-type diet consisting of $15 \%$ (wt/wt) cocoa butter and $0.25 \%$ (wt/wt) cholesterol (Diet W; abDiets) for the entire 11 week experimental period. After 2 weeks of adaptation to the western-type diet, specific patterns of shear stress were applied to the right carotid artery by the surgical placement of a shear stress modifier device called "cast". The cast consists of 2 longitudinal halves of a cylinder with a cone-shaped lumen, which imposes a fixed geometry on the vessel wall. Such geometry produces vortices downstream, therefore exposing the artery wall to oscillatory shear stress (OSS) in the downstream region and a low shear stress (LSS) in the region upstream of the blood flow $[5,28]$. Such distinct patterns of shear stress induce atherosclerotic plaques with different compositions. LSS-induced plaques present features of vulnerable plaques, whereas OSS-induced plaques display a more stable phenotype $[5,18,28,29]$.

The cast was implanted as previously described [18,29]. Briefly, the animals were anesthetized by isoflurane inhalation, and the anterior cervical triangles were accessed by a sagittal anterior neck incision. The right carotid artery was carefully detached from connecting tissue and, sequentially, the cast halves were placed around and fixed with silk suture. After closing the wounds, the animals were allowed to
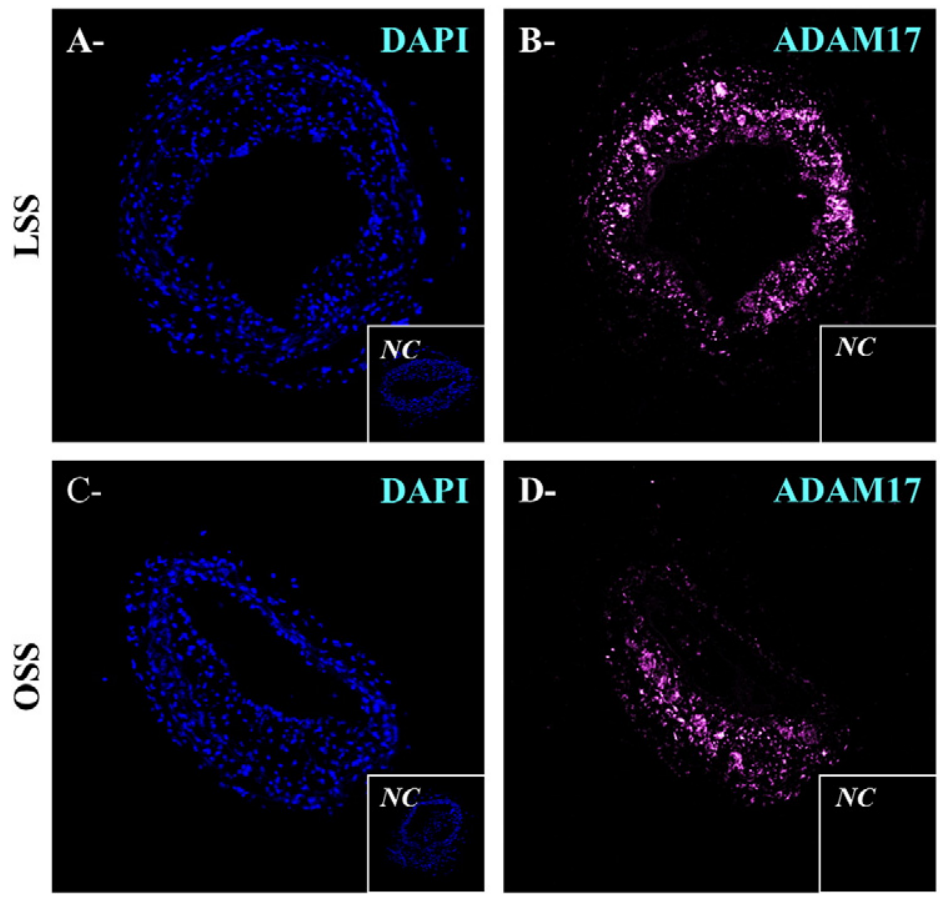

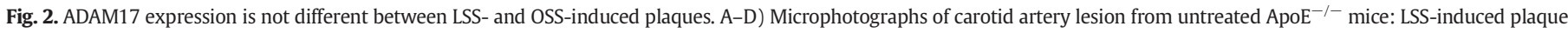

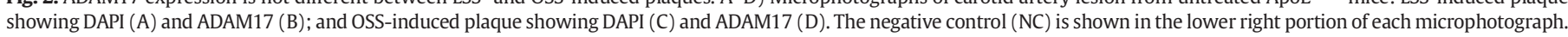
E) Quantification for ADAM17 expression. n.s.: non-significant (Mann-Whitney nonparametric test). Data were expressed as mean \pm SEM. 

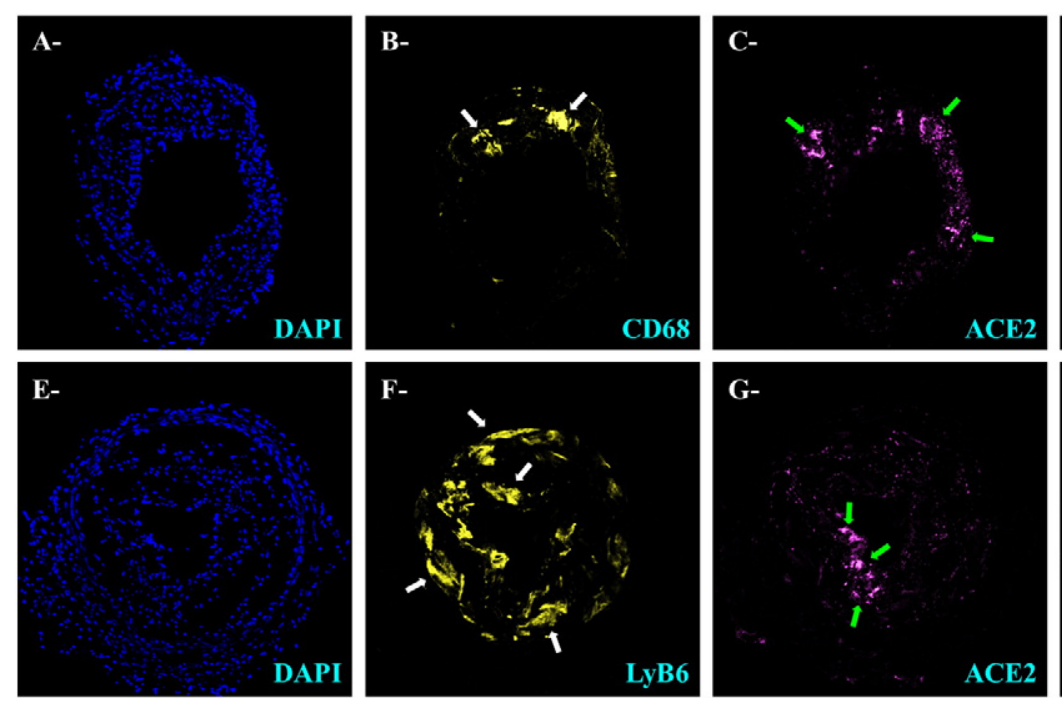
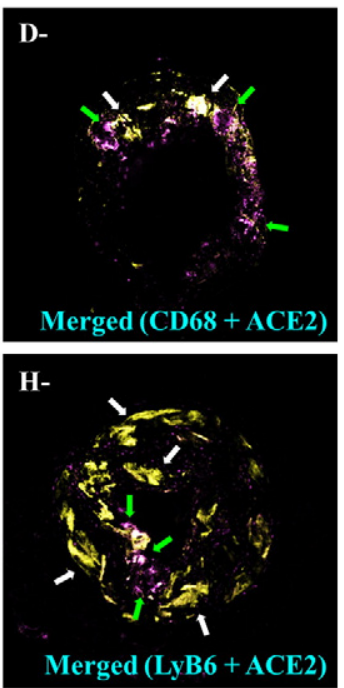

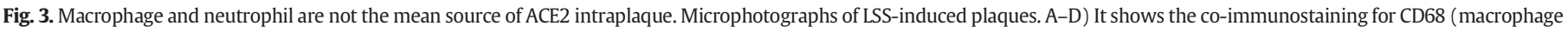

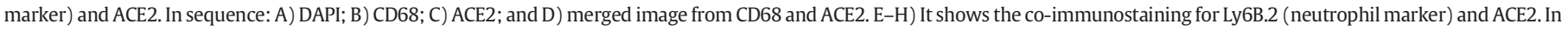
sequence: E) DAPI; B) Ly6B.2; C) ACE2; and D) merged image from Ly6B.2 and ACE2.

recover. The last 3 weeks prior to euthanasia (from weeks 8 to 11), mice were randomly assigned to receive either vehicle or diminazene [15 mg/kg per day] subcutaneously. After 9 weeks after of cast implantation (a total of 11 weeks' feeding with western diet), the mice were anesthetized (ketamine $100 \mathrm{mg} / \mathrm{kg}$, xylazine $10 \mathrm{mg} / \mathrm{kg}$ ) and blood samples were collected by cardiac puncture. Immediately following cardiac puncture, the animals were perfused with PBS and the carotid artery aortic roots removed and frozen in a cryoembedding medium for histological analysis. The entire aortas were dissected from the ascending portion until the bifurcation of the iliac arteries and fixed in $4 \%$ paraformaldehyde for $24 \mathrm{~h}$ for atherosclerotic lesion analyses. This animal study was approved by local ethics committee and Swiss Regulatory
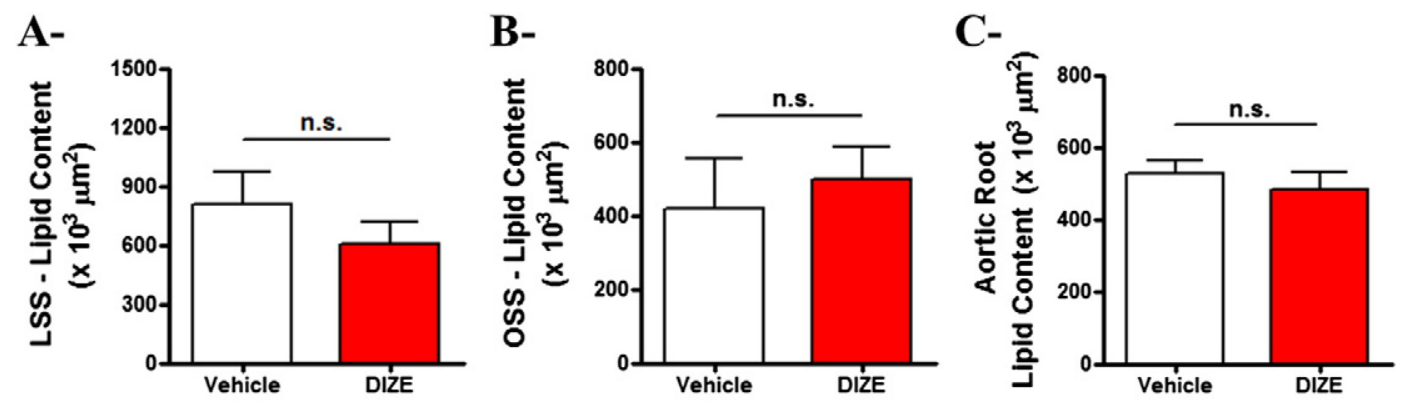

D-
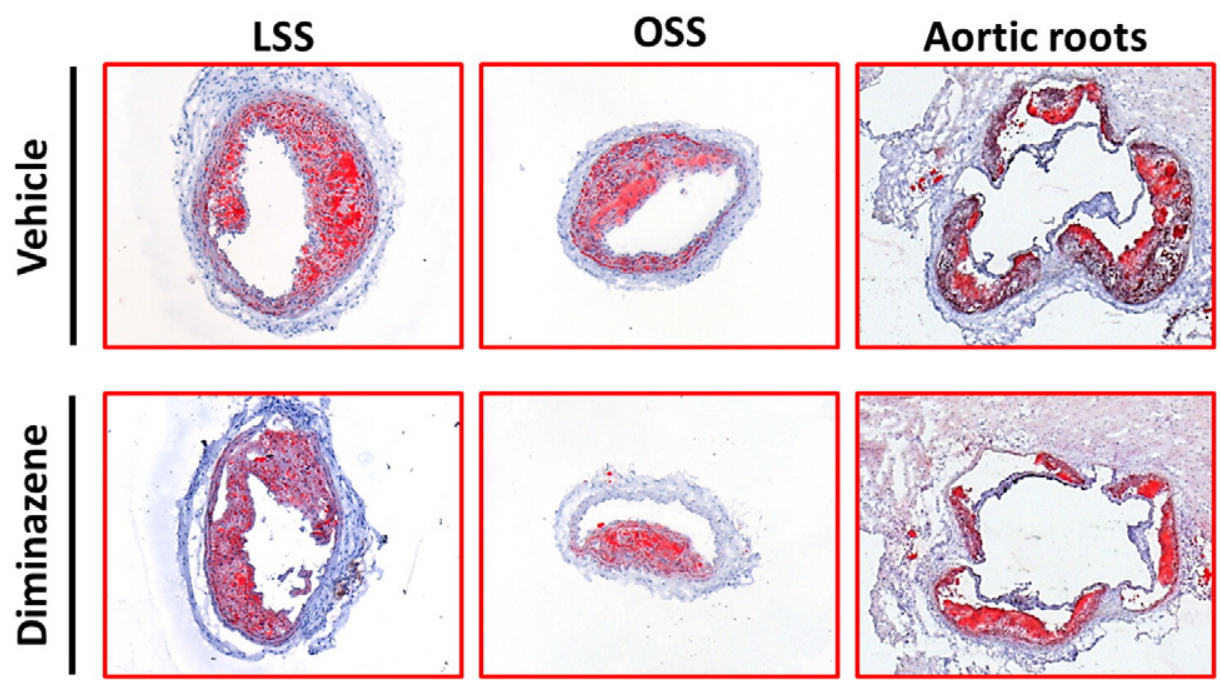

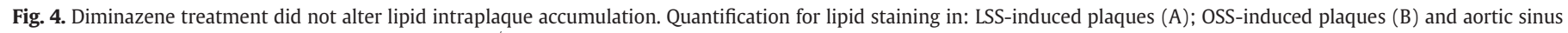

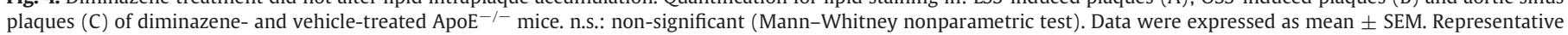
microphotographs (D). 
Table 1

Serum lipid profile.

\begin{tabular}{lccl}
\hline Mouse profile & $\begin{array}{l}\text { Vehicle } \\
(\mathrm{n}=12)\end{array}$ & $\begin{array}{l}\text { DIZE } \\
(\mathrm{n}=10)\end{array}$ & p-Value \\
\hline Body weight day 0 $(\mathrm{g})$ & $24.16 \pm 0.43$ & $24.67 \pm 0.51$ & 0.4491 \\
Body weight at sacrifice $(\mathrm{g})$ & $32.29 \pm 0.52$ & $33.10 \pm 0.56$ & 0.3045 \\
Oil Red O in the aorta $(\%$ of total area $)$ & $7.27 \pm 0.93$ & $8.66 \pm 2.08$ & 0.5337 \\
Total cholesterol $(\mathrm{mmol} / \mathrm{L})$ & $25.76 \pm 1.97$ & $25.55 \pm 2.13$ & 0.9440 \\
HDL $(\mathrm{mmol} / \mathrm{L})$ & $4.881 \pm 0.307$ & $4.953 \pm 0.459$ & 0.8940 \\
LDL $(\mathrm{mmol} / \mathrm{L})$ & $21.11 \pm 1.58$ & $21.66 \pm 2.02$ & 0.8297 \\
Triglycerides $(\mathrm{mmol} / \mathrm{L})$ & $0.894 \pm 0.088$ & $0.631 \pm 0.041$ & $0.0343^{*}$ \\
Free fatty acids $(\mathrm{mmol} / \mathrm{L})$ & $0.588 \pm 0.061$ & $0.653 \pm 0.066$ & 0.4968 \\
\hline
\end{tabular}

Data are expressed as mean \pm SEM.

$\mathrm{p}$ value calculated according to Unpaired t test.

* $\mathrm{p}<0.05$.

Authorities (authorization number 2026.4) and it is in accordance with the guidelines from Directive 2010/63/EU of the European Parliament on the protection of animals used for scientific purposes.

\subsection{Oil Red $O$ staining}

After sacrifice, the aortic tree were cleaned and stripped of fat on the adventitia and fixed in $4 \%$ paraformaldehyde for $24 \mathrm{~h}$. Later, aortas were carefully opened longitudinally and pinned with small needles on a Petri dish coated with silicon to expose the area of definable lesion covering the luminal surface. Oil Red $\mathrm{O}$ staining was performed as previously described [30]. The images were captured and the lesions were quantitated by calculating the percentage of the total surface area using Image J software.

The right carotid artery was macroscopically cut in three portions: upstream region of the cast device (LSS), at cast level (high shear stress
[HSS]) and downstream of the cast (OSS) and frozen in OCT. The LSS and OSS portions and aortic sinus from all mice were serially cut in $7 \mu \mathrm{m}$ transversal sections and stained with Oil Red $\mathrm{O}$ as described previously [31]. The sections were counterstained with Mayer's hemalum and rinsed in distilled water. Quantifications were performed using the MetaMorph software. Data were calculated as ratios of stained area on total lesion area.

\subsection{Sirius Red staining}

Intraplaque collagen content was assessed as described elsewhere [18]. Briefly, $7 \mu \mathrm{m}$ transversal sections of carotid plaque (LSS and OSS regions) and aortic sinus were rinsed with water and incubated with $0.1 \%$ Sirius Red (Sigma Chemical Co, St Louis, MO) in saturated picric acid for 90 min. Sequentially, sections were rinsed twice with $5 \%$ acetic acid in water for $10 \mathrm{~s}$, then immersed in absolute ethanol three times before clearing in xylene twice and cover-slipping. The sections were photographed using identical exposure settings under normal light microscopy. Intraplaque total collagen content was quantified by the MetaMorph software. Data were calculated as percentages of stained area on total lesion area.

\subsection{Immunostaining in carotid plaques and aortic sinus}

Carotid (LSS and OSS regions) and aortic sinus plaques were serially cut in $7 \mu \mathrm{m}$ transversal sections and stained as previously described [31]. Eleven sections per staining (separated by $45 \mu \mathrm{m}$ from each other) from each mouse specimen were fixed in acetone and immunostained with the following specific antibodies: anti-ACE2 (dilution $5 \mu \mathrm{g} / \mathrm{mL}$, Abcam, Cambridge, UK), anti-mouse CD68 (macrophages, dilution: 1:400; ABD Serotec, Dusseldorf, Germany), anti-mouse Ly6G

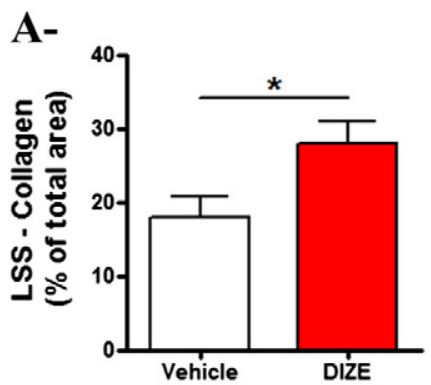

D-

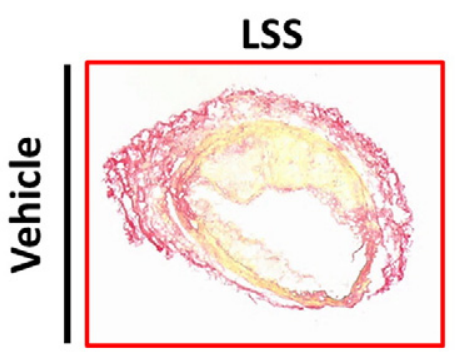

B-
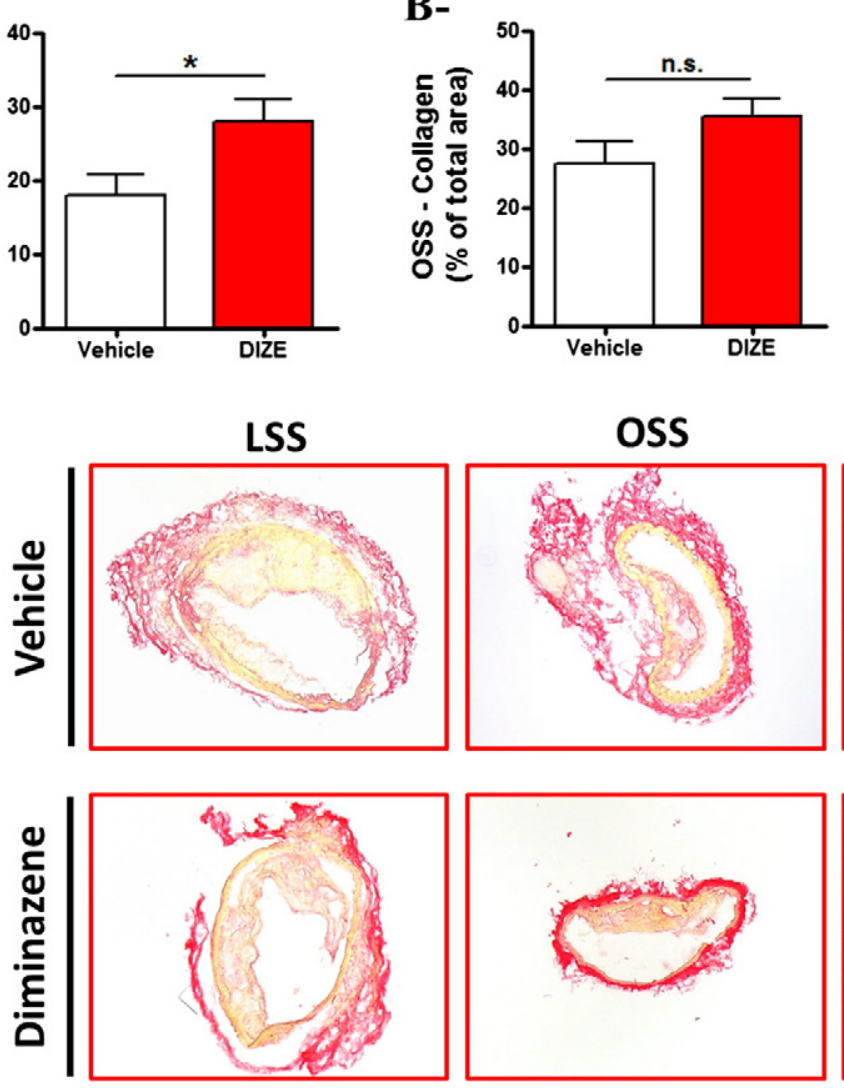

OSS
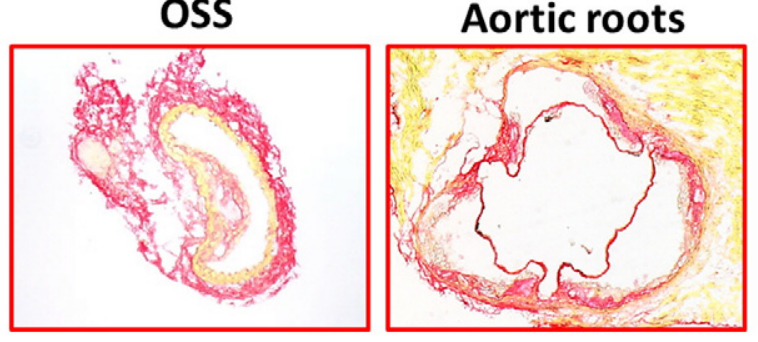

C-

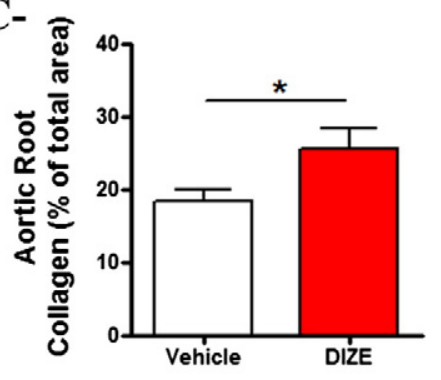

Aortic roots
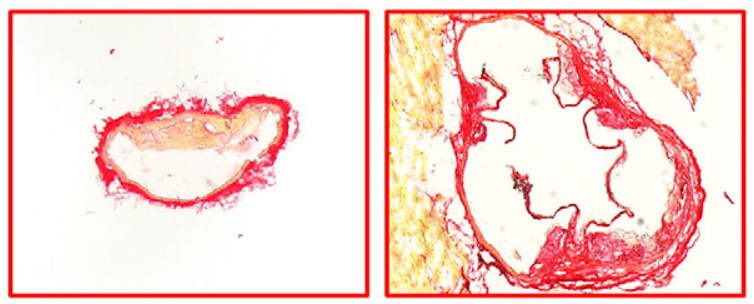

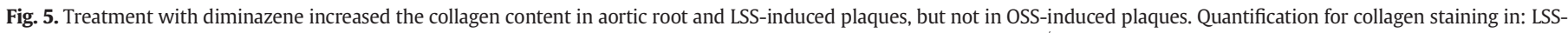

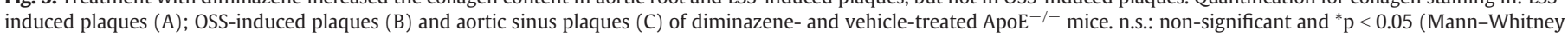
nonparametric test). Data were expressed as mean \pm SEM. Representative microphotographs (D). 
(neutrophils, dilution: 1:100; BD Pharmingen ${ }^{\mathrm{TM}}$, San Jose, CA), antimouse MMP-9 (dilution: 1:60; R\&D Systems), anti-mouse Ly6B.2 (neutrophils, dilution: 1:200; AbD Serotec, Kidlington, UK), rabbit anti-mouse ADAM-17 (dilution: $10 \mu \mathrm{g} / \mathrm{mL}$; Abcam, Cambridge, UK), rat anti-mouse ICAM-1 (dilution: 1:200; Abcam, Cambridge, UK) and rabbit anti-mouse VCAM-1 (dilution: 1:200; Abcam, Cambridge, UK)

For the images obtained in brightfield microscopy, the quantifications were performed with the MetaMorph software and the data were calculated as percentages of stained area from the total lesion area (macrophages and MMP-9) or number of cells per millimeter squared (neutrophils). Fluorescent images were obtained on a confocal microscope equipped with a digital imaging system (Carl Zeiss LSM 700, Zeiss, Baden-Württemberg, Germany) and fluorescence intensity was quantified by Image J software (NIH, Bethesda, MD, USA).

\subsection{Flow cytometry analysis of ICAM-1 and VCAM-1 in HVEC}

HVEC $\left(1.6 \times 10^{4}\right.$ cells/well $)$ were plated in 6 -well plates and allowed to adhere overnight. Cells were then treated with control medium (CTL) or diminazene (at 0.2 or $2 \mathrm{mg} / \mathrm{mL}$ ) in the presence or absence of $20 \mathrm{ng} / \mathrm{mL}$ of human recombinant TNF-alpha (R\&D Systems Ltd, Abingdon, UK) for $3 \mathrm{~h}$. Floating and adhering cells were collected from culture wells by repeatedly washing and by trypsinization. Subsequently, cells were stained with propidium iodide ([PI], Sigma Aldrich) to determine cell viability, and anti-human VCAM-1/CD106-Phycoerythrin or antihuman ICAM-1/CD54-Phycoerythrin (Pharmingen ${ }^{\mathrm{TM}}$, San Jose, CA) according to the manufacturer's instructions. The samples were analyzed by flow cytometry with a FACS Calibur (Becton Dickinson). Ten thousand events for each sample were acquired. Results were expressed as mean fluorescence intensity.

\subsection{Dosage of serum lipid profile and inflammatory markers}

Blood samples were collected by cardiac puncture and maintained at room temperature for $20 \mathrm{~min}$. The serum was sequentially obtained by centrifugation ( $2500 \mathrm{rpm}$ for $10 \mathrm{~min}$ ). The lipids were measured by photometric enzymatic reaction using commercial available kits (glucose cat.\#11447513; triglycerides cat.\#12016648; total cholesterol cat.\#12016630; low-density lipoprotein cat.\#03038661; high-density lipoprotein cat.\# 03030024 122; free fatty acids cat.\#11383175001; from Roche Diagnostics GmbH, Mannheim, Germany) using the chemistry analyzer Roche Hitachi 902 (Roche Diagnostics GmbH, Mannheim, Germany). The assay was performed as described in the instruction manual. The concentrations were expressed as $\mathrm{mmol} / \mathrm{L}$.

Serum cytokine levels (IFN- $\gamma$, IL-10, IL-12p70, IL-17A, IL-1 $\beta$, IL-6, IL-10, MCP-1, TNF- $\alpha$, VEGF) were determined by using bead based multiplex suspension array kits with Luminex technology on a BioPlex (Bio-Rad, Hercules, CA, USA). The assay was performed following the manufacturer's instructions and concentrations were expressed as $\mathrm{pg} / \mathrm{mL}$.

\subsection{Data and statistical analysis}

Unpaired t test was used for all comparisons between diminazeneand vehicle-treated mice on LSS- and OSS-induced plaques. One-way ANOVA followed by Bonferroni post-test was used to evaluate ICAM-1
A-

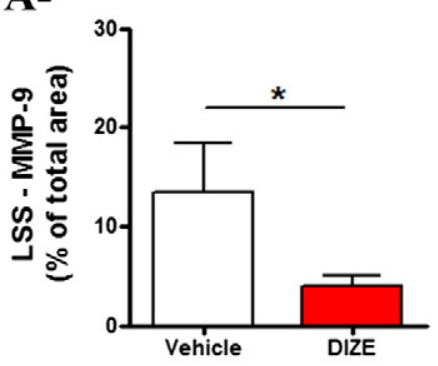

D-
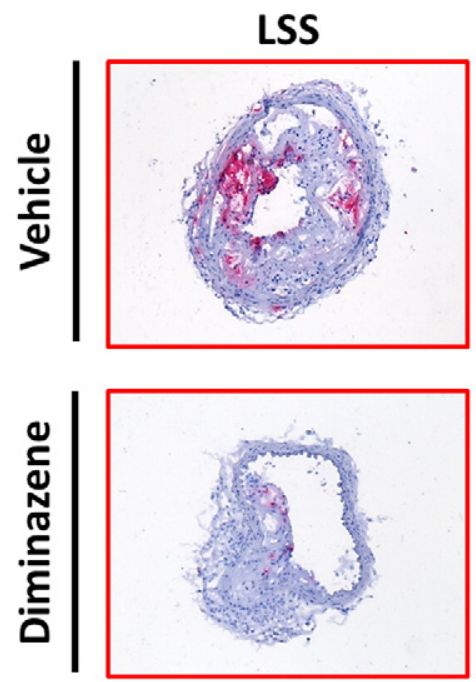

B-

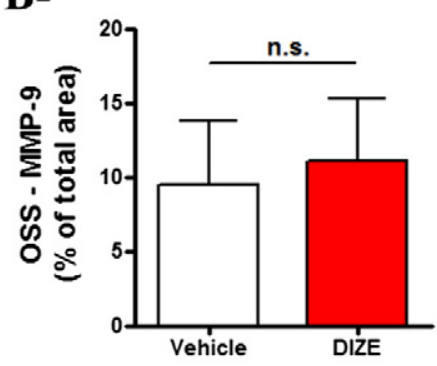

OSS
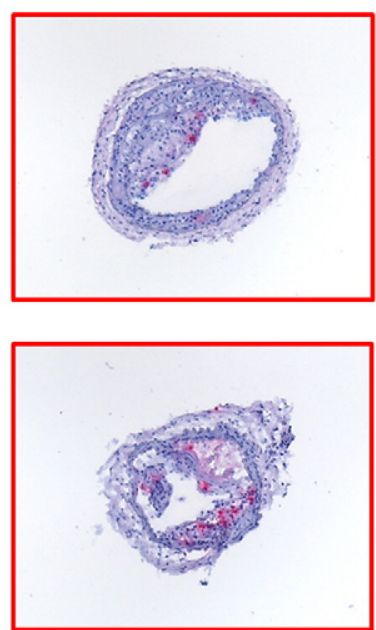

C-

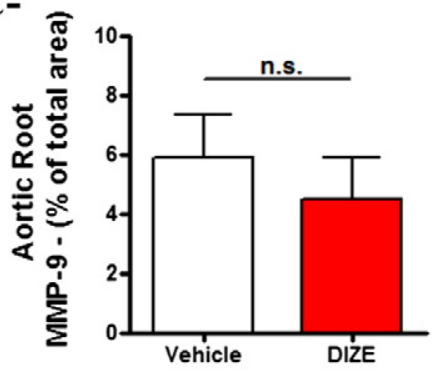

Aortic roots
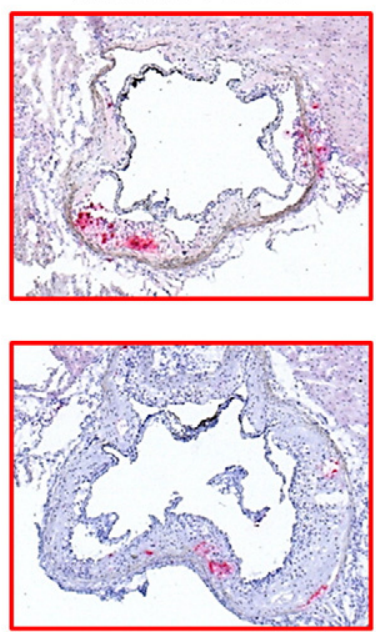

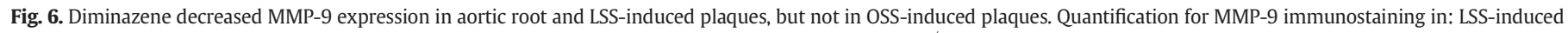

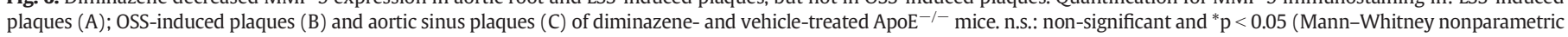
test). Data were expressed as mean \pm SEM. Representative microphotographs (D). 
expression in HVEC. Statistical analysis was performed using GraphPad Prism software (GraphPad, San Diego, CA, USA). A value of $p<0.05$ was considered significant and the results are expressed as mean \pm SEM.

\section{Results}

3.1. Intraplaque ACE2 expression varies depending on the local pattern of shear stress

ACE2 protein expression in atherosclerotic plaques was assessed by immunostaining. We found that ACE2 was strongly expressed in the LSS-induced plaques and aortic sinus plaques (Fig. 1A-C). Interestingly, this enzyme was weakly expressed or even not detected in OSS-induced plaques (Fig. 1B), indicating that ACE2 expression might be modulated by local shear stress forces or may differ according to the intraplaque composition and environment. No difference in ACE2 expression was observed between diminazene or vehicle treated mice (data not shown).

One possible explanation for the diminishing ACE2 levels in OSSinduced plaque would be an increased shedding from the tissues by $\mathrm{A}$ disintegrin and metalloproteinase (ADAM17) [32]. ADAM17 is involved in the shedding of several transmembrane proteins, including ACE2 [33]. Based on that, the intraplaque expression of ADAM17 was evaluated and no difference was observed between LSS- and OSS-induced plaques (Fig. 2).

Therefore, apparently, an increased expression of ADAM-17 is not associated with the lower presence of ACE2 in OSS-induced plaques.

In order to better understand the function of ACE2 within the atherosclerotic lesion, ACE2 was co-immunostained with CD68 and Ly6B.2, specific markers for macrophage and neutrophil. It was observed that ACE2 was not intensely co-localized with CD68 or Ly6B.2
(Fig. 3), suggesting that macrophage and neutrophil are not the mean sources of ACE2 intraplaque.

\subsection{Diminazene ameliorates the composition of vulnerable plaque}

Lipid content within LSS-induced carotid plaques presented a tendency to be reduced in the diminazene treated mice (25\% of reduction), but no statistical significance was observed ( $p=0.308$, Fig. 4A and D). The treatment with diminazene did not alter lipid content in OSSinduced plaque and aortic sinus (Fig. 4B, C and D). Similarly, atherosclerotic lesion size in the aorta tree was not altered by diminazene treatment (Table 1).

Although diminazene treatment did not significantly alter the atherosclerotic plaque lipid content and size, it did ameliorate plaque composition. Diminazene significantly increased the intraplaque total collagen content in LSS-induced and aortic sinus plaques, as compared to the vehicle group (Fig. 5A, C and D respectively). Accordingly, diminazene treatment resulted in a reduced MMP-9 expression in LSS-induced plaques (Fig. 6A), but no change was observed in aortic sinus plaques (Fig. 6C and D). Additionally, diminazene treatment decreased macrophage infiltration in LSS-induced and aortic sinus plaques, when compared to the vehicle group (Fig. 7A, C and D). Despite a tendency of reduced neutrophil infiltration in LSS-induced and aortic sinus plaques, no statistical difference was observed (Fig. 8A-D), 32\% and $37 \%$ of reduction ( $p=0.417$ and $p=0.152$, for LSS-induced and aortic sinus plaques, respectively). Diminazene did not alter the intraplaque smooth muscle content, evaluated by immunostaining for alpha actin in aortic root plaques (data not shown).

Interestingly, none of the diminazene-mediated beneficial effects on LSS-induced and aortic sinus plaques was observed in OSS-induced plaques. Diminazene did not change the intraplaque collagen content

\section{A-}

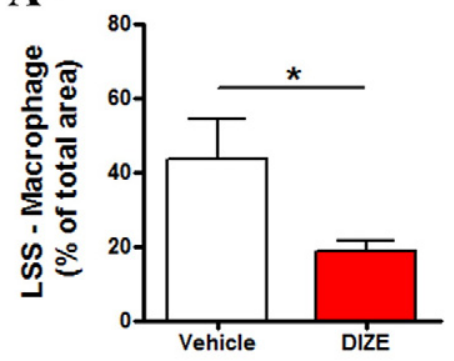

D-
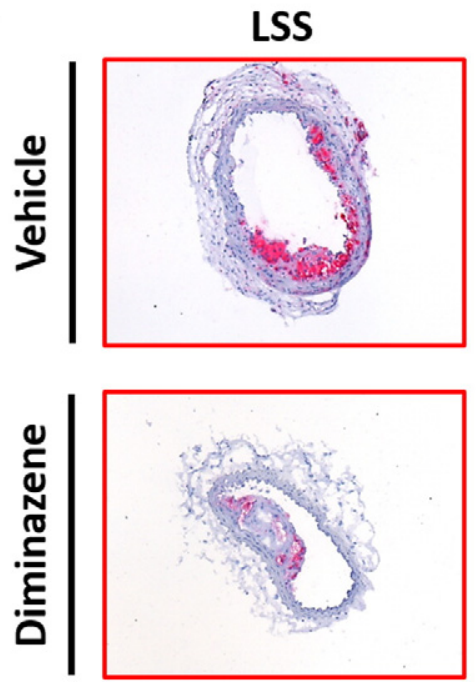

B-

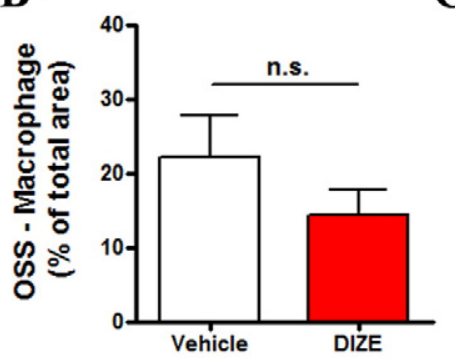

OSS
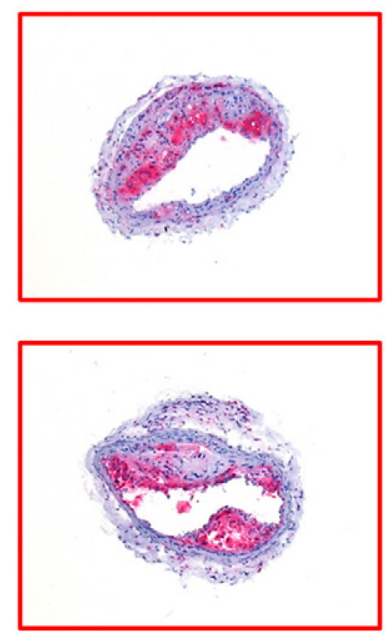

C-

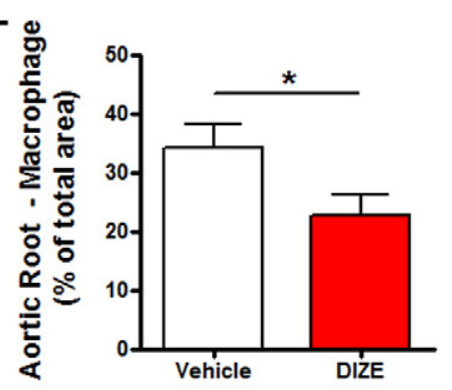

Aortic roots
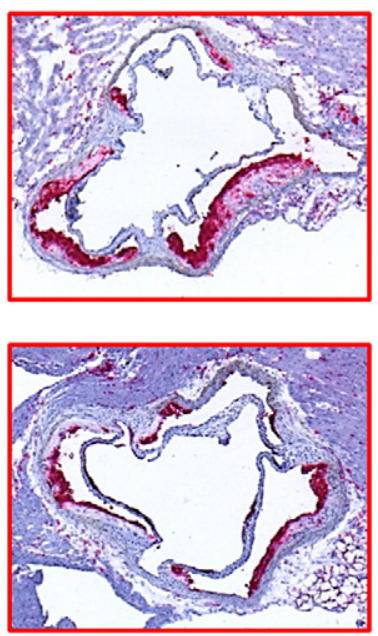

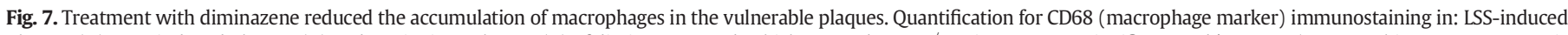

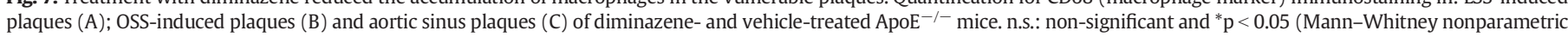
test). Data were expressed as mean \pm SEM. Representative microphotographs (D). 
(Fig. 5B and D), MMP-9 expression (Fig. 6B and D), macrophage infiltration (Fig. 7B and D), and neutrophil infiltration (Fig. 8B and D) in OSSinduced plaques as compared to vehicle control. These data suggest that diminazene acts exclusively on plaques expressing ACE2 or it actions depend on the plaque phenotype.

\subsection{Diminazene reduces triglycerides serum levels but does not alter cholesterol levels}

At the end of the experiment, total cholesterol, low-density lipoprotein cholesterol, high-density lipoprotein cholesterol or free fatty acid serum levels were assessed. Diminazene treatment significantly reduced triglyceride serum levels. No other parameters were altered (Table 1).

\subsection{Diminazene diminishes ICAM-1 and VCAM-1 expression}

To examine the mechanism by which diminazene decreased macrophage infiltration, ICAM-1 and VCAM-1 expression on aortic root plaques and HVEC, stimulated or not with TNF- $\alpha$, were evaluated. Diminazene treatment decreased intraplaque expression of ICAM-1 and VCAM-1 (Fig. 9A-J). In HVEC, diminazene at $2 \mathrm{mg} / \mathrm{mL}$ reduced baseline ICAM-1 expression when compared to control group. As expected, TNF- $\alpha$ significantly increased ICAM- 1 expression on HVEC, while diminazene abolished its effect (Fig. 9M). Of note: 1) ACE2 was well expressed on HVEC as it was detected by western blot (Fig. 9L); 2) VCAM-1 was not detected in HVEC, even after incubation with TNF- $\alpha$; and 3) diminazene at $0.2 \mathrm{mg} / \mathrm{mL}$ did not alter ICAM- 1 expression on HVEC (Fig. 9L).

\subsection{Treatment with diminazene diminishes inflammation in $\mathrm{ApoE}^{-1-}$ mice}

The circulatory levels of key cytokines and chemokines in the atherosclerotic condition were measured in the serum of diminazenetreated and untreated mice. The long-term treatment with diminazene significantly reduced IL-1ß, IL-6 and VEGF serum levels (Table 2). Although no statistical significance was reached, diminazene treatment produced a strong tendency to reduce MCP- 1 serum levels ( $\mathrm{p}=$ 0.085 , Table 2). Diminazene slightly reduced IFN- $\gamma$, IL-10, IL-12p70, IL-17A, and TNF- $\alpha$ serum levels, but no statistical significance was measured (Table 2).

\section{Discussion}

Shear stress forces are one of the main factors modulating atherosclerosis. These biomechanical elements influence several molecular mechanisms and control atherosclerotic plaque composition [3-5]. In the present study, we found that ACE2, a major enzyme of the renin angiotensin system, was expressed in LSS-induced atherosclerotic plaques in the carotid artery and aortic sinus; however, poor to undetectable expression was seen in OSS-induced plaques in the carotid artery. This interesting finding is in keeping with previous reports indicating a differential modulation of RAS components by distinct shear stress patterns. It has been documented that oscillatory flow induces a timedependent change in AT1 receptor expression on endothelial cells [34]. Moreover, a pronounced expression of AT1 receptor on the endothelial cells of the inner curvature of mouse aortic arch (atheroprone regions of the aortic arch) was found, while AT1 expression was almost absent on the outer curvature [34]. In accordance, we have reported

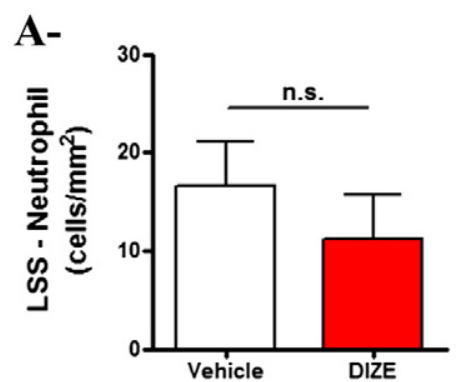

D-
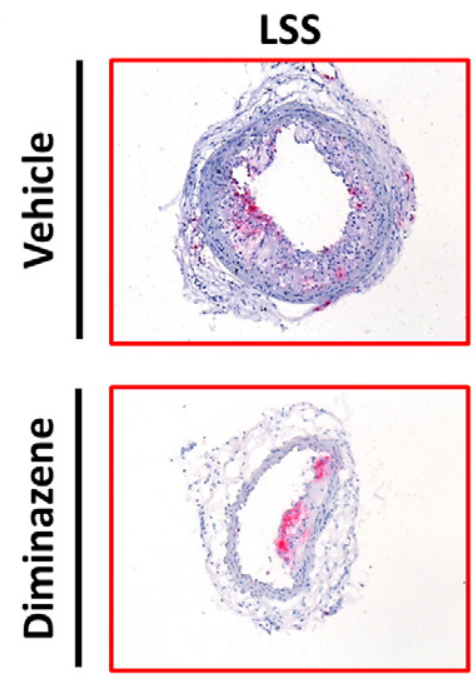
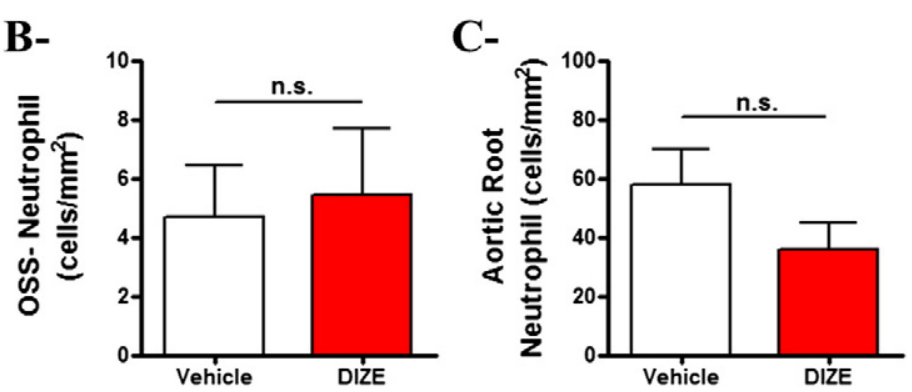

oss

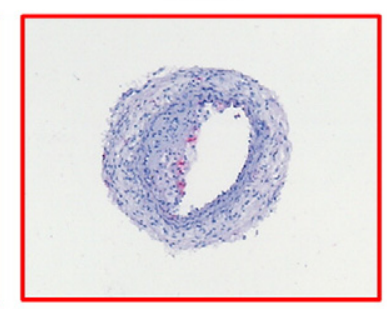

Aortic roots
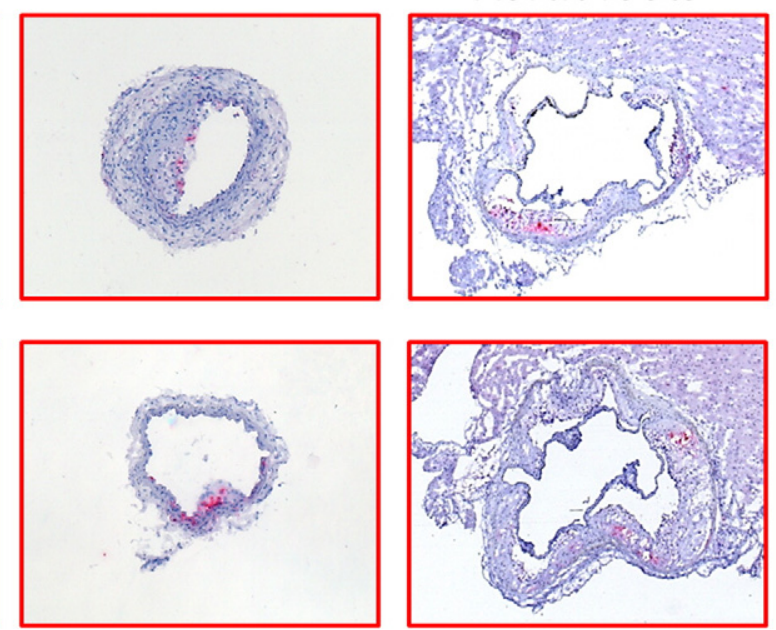

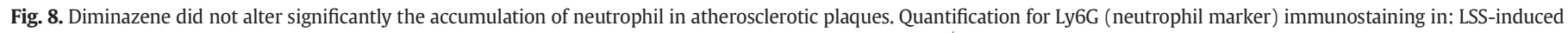

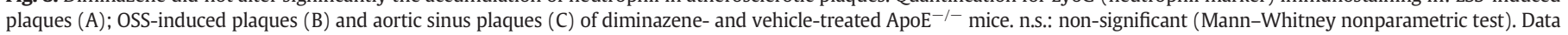
were expressed as mean \pm SEM. Representative microphotographs (D). 

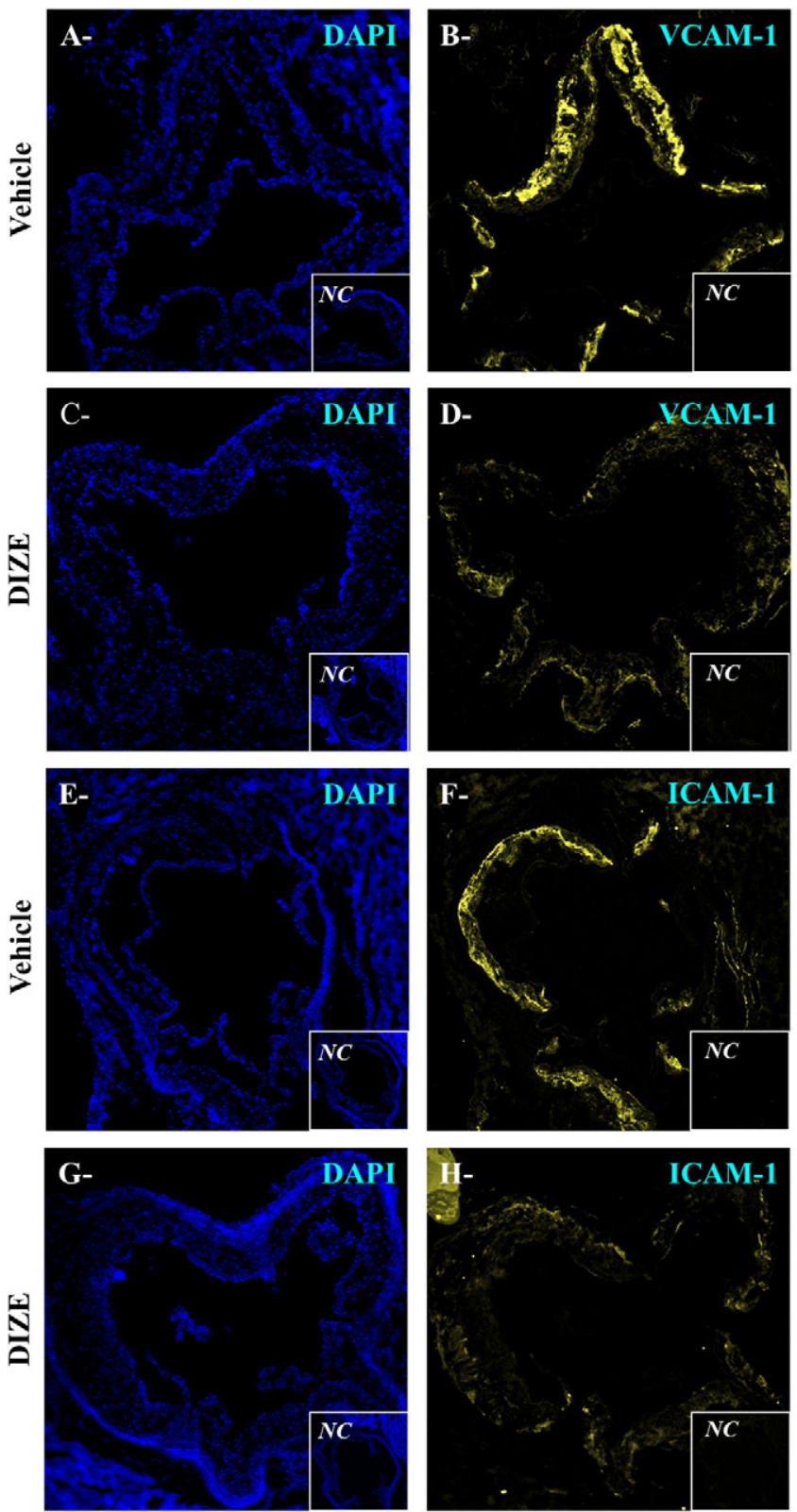

I-

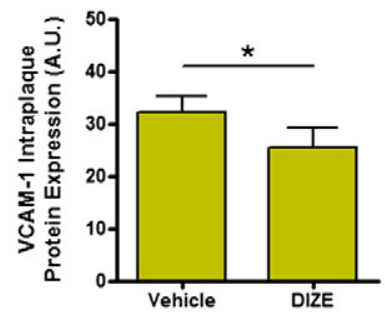

J-

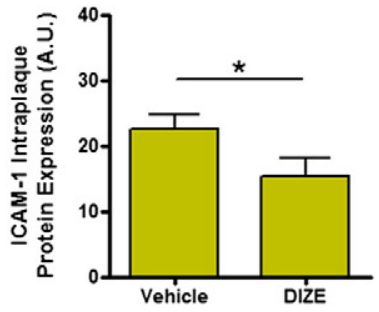

L-

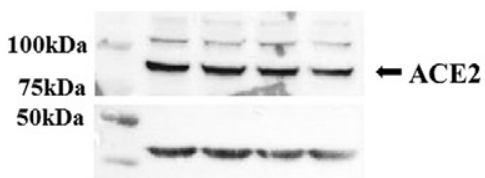

M-

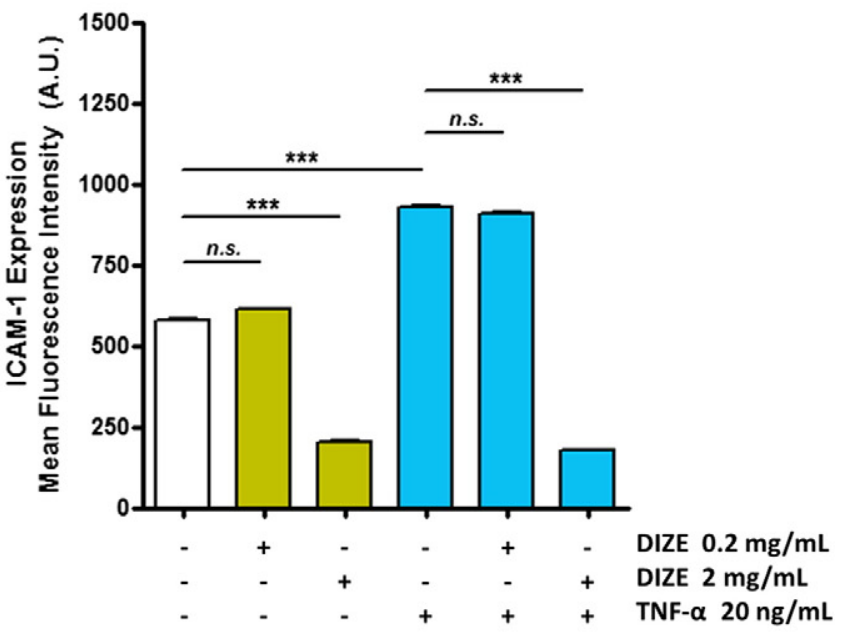

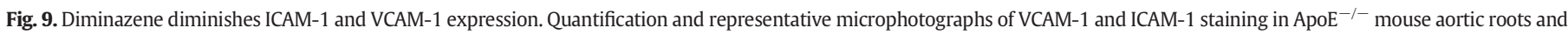

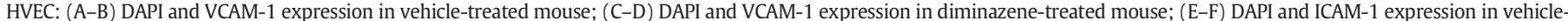

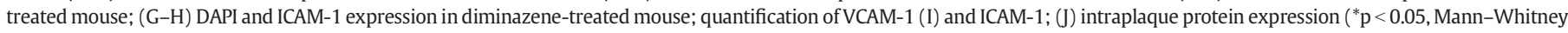

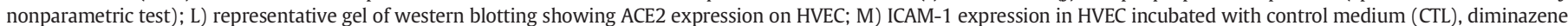

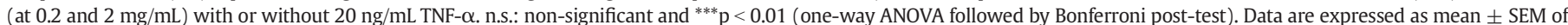
mean fluorescence intensity.

Table 2

Serum cytokines.

\begin{tabular}{llll}
\hline $\begin{array}{l}\text { Cytokines } \\
(\mathrm{pg} / \mathrm{mL})\end{array}$ & $\begin{array}{l}\text { Vehicle } \\
(\mathrm{n}=19)\end{array}$ & $\begin{array}{l}\text { DIZE } \\
(\mathrm{n}=15)\end{array}$ & p-Value \\
\hline IFN- $\gamma$ & $25.14 \pm 3.143$ & $23.28 \pm 5.958$ & 0.7654 \\
IL-10 & $128.6 \pm 23.58$ & $109.9 \pm 25.33$ & 0.5924 \\
IL-12p70 & $152.5 \pm 21.18$ & $126.1 \pm 20.16$ & 0.3940 \\
IL-17 & $225.2 \pm 17.85$ & $185.6 \pm 27.51$ & 0.2271 \\
IL-1B & $677.2 \pm 93.11$ & $448.3 \pm 22.44$ & $0.0358^{*}$ \\
IL-6 & $38.67 \pm 7.699$ & $19.33 \pm 1.865$ & $0.0402^{*}$ \\
MCP-1 & $205.9 \pm 19.42$ & $165.5 \pm 11.73$ & 0.0856 \\
TNF- $\alpha$ & $2362 \pm 212.6$ & $2285 \pm 232.5$ & 0.8099 \\
VEGF & $1199 \pm 217.3$ & $519.4 \pm 77.13$ & $0.0180^{*}$ \\
\hline
\end{tabular}

Data are expressed as mean \pm SEM.

$\mathrm{p}$ value calculated according to Unpaired t test.

* $\mathrm{p}<0.05$ that angiotensinogen, ACE, and AT1 receptor genes were up-regulated in the upstream regions of human plaques as compared to the downstream (regions with distinct patterns of shear stress) [18].

One well-known mechanism responsible for local depletion of ACE2 is an augmented shedding by ADAM17 [32]. Here we observed that ADAM17 was well expressed in both LSS- and OSS-induced plaques; however, no difference in expression between them was observed. As a limitation, the intraplaque activity of ADAM17 was not measured, and despite the fact that ADAM17 expression is similar between LSSand OSS-induced plaques, it could be possible that this enzyme is more active in the OSS than in the LSS region. Indeed, it has been reported that ADAM17 is overactive in human carotid atherosclerotic plaques of type 2 diabetes mellitus patients (condition associated with accelerated atherosclerosis), which was associated with a decrease of tissue inhibitor of metalloproteinase 3, an endogenous inhibitor of ADAM17 
[35]. Nevertheless, the mechanism by which ACE2 is poorly expressed in OSS-induced plaques remains to be elucidated.

Interestingly, three weeks of diminazene treatment ameliorated the composition of LSS-induced carotid and aortic sinus plaques, while it did not affect OSS-induced carotid plaque. The first ACE2 activator was developed in 2008 by the group of Prof. Raizada [36]. Using a virtual molecular docking selection strategy, 139,735 molecules (library of the National Cancer Institute, US) were screened to access the ability to interact with a specific pocket of ACE2 and sustain a favorable conformation for optimal enzyme activity [36]. The highest scoring compounds were obtained and assayed in vitro to evaluate their abilities to enhance ACE2 catalytic activity. One of the effective compounds was called XNT, which showed an enhanced catalytic rate by increasing the velocity of the enzyme 2-fold [36-39]. More recently, diminazene was identified as another ACE2 activator compound, but this time using a library of 1217 chemicals from the Food and Drug Administration (FDA)-approved compounds, and therefore, compounds with extensive information on bioavailability, toxicity, and safety [26].

Diminazene was first described as an antitrypanosomal drug. This compound was used for the treatment of early-stage sleeping sickness, an infection caused by Trypanosoma brucei [40]. Interestingly, early studies have shown that diminazene might produce a hypotensive side-effect that was related to direct and indirect effects on the cardiovascular system [40]. Diminazene actions on the cardiovascular system have been documented in different conditions. For instance, diminazene attenuates pulmonary hypertension [27], reduces damages in cardiac [41] and stroke ischemia [42], improves erectile function [43], as well as other beneficial effects $[44,45]$.

The mechanisms by which diminazene produces beneficial cardiovascular outcomes are not completely understood. Evidence has demonstrated that diminazene acts by modifying ACE2 activity and, as a result, decreases Ang II and increases Ang-(1-7) levels [19]. In fact, coadministration of C-16, ACE2 inhibitor, abolished the protective effects of diminazene on pulmonary hypertension [27] and post-myocardial infarction [41]. Moreover, it has been shown that treatment with diminazene (15 mg/kg/day) increased Ang-(1-7) circulating level and enhanced endothelial function in a model of diabetes [46]. Similarly, diminazene at $30 \mathrm{mg} / \mathrm{kg} /$ day elevated plasma Ang-(1-7) concentrations in $\mathrm{Ldll}^{-/-}$mice [45]. Supporting these observations, co-administration of A-779, an Ang-(1-7)-Mas receptor antagonist, attenuates the beneficial action of diminazene on cerebral ischemia [42] and glaucoma [44]. Additionally, diminazene may also upregulate the expression of ACE2 [27], indicating that this compound not only augments intrinsic enzyme activity, but also increases the total enzyme expression. The relevance of each mechanism most likely depends on the treatment condition and, despite both mechanisms, synergistical output to increase ACE2 activity, it still remains to be elucidated. In our study, we observed that diminazene acted only in atherosclerotic plaque expressing ACE2, suggesting that the effects of this compound depend on ACE2. However, as in the present study it was not possible to assess the levels of Ang II and Ang-(1-7) within the atherosclerotic plaques, the mechanism by which diminazene improves the plaque stability should be prudently interpreted.

The atheroprotective actions of ACE2 have been shown in a variety of studies. This enzyme is expressed within animal [20,22] and human atherosclerotic plaques [21] and located in different cell types present in the lesions, such as endothelial cells, vascular smooth muscle cells and macrophages [14]. It has been shown that ACE2 overexpression by gene transfer diminished lesion progression in a rabbit model of atherosclerosis induced by endothelial injury and atherogenic diet [22]. Likewise, overexpression of ACE2 in $\mathrm{ApoE}^{-1-}$ mice attenuates atherosclerotic lesion size [47], indicating a beneficial role of ACE2 against atherosclerosis development. The protective action of ACE2 on atherosclerosis is also supported by data on ACE2-deficient mice model. ACE2-deficiency in both low-density lipoprotein receptor-deficient $\left(\mathrm{Ldll}^{-/-}\right.$) and $\mathrm{ApoE}^{-/-}$backgrounds presented larger atherosclerotic lesions when compared to their respective controls [23-25]. In the present study, three weeks of treatment with diminazene did not alter the atherosclerotic lesion size. Despite apparently inconsistent data, it is reasonable to infer that the short period of treatment was not sufficient to reduce the plaque size and/or that the pharmacological activation of ACE2 by diminazene is less effective compared to that of gene transfer overexpression. Nonetheless, diminazene improved the lesion composition for a more stable phenotype, diminishing the infiltration of inflammatory cells and increasing collagen deposition. In support of our data, Dong and co-workers [22] showed that ACE2 overexpression enhances plaque stability in a rabbit model of atherosclerosis by reducing macrophage infiltration, decreasing lipid deposition, lowering MMP-3 and MMP-9 activities, and increasing collagen content. Similarly, ACE2 gene deletion increased atherosclerotic vulnerability by increasing the intraplaque inflammatory profile [23-25]. Therefore, the pharmacological activation of ACE2 by diminazene appears to be consistent with the previous studies evaluating ACE2 overexpression or deletion.

Interestingly, in the present study, we reported that diminazene action depends on the local pattern of shear stress. In LSS and aortic sinus plaques, diminazene increased collagen content, decreased MMP-9 expression and reduced macrophage infiltration, while in OSS-induced carotid plaques, none of the studied parameters were altered. The possible lack of action in the OSS region might be due to the fact that ACE2 was poorly expressed in such plaques. It is reasonable to argue that, since ACE2 is widely expressed in the cardiovascular system, shifting the balance between Ang-(1-7) and Ang II, it is possible that increased Ang-(1-7) circulating levels would modulate OSS-induced plaque phenotype. Notwithstanding, we previously reported that long-term treatment with Ang-(1-7) ameliorates the phenotype of LSS-induced plaques, but did not affect OSS-induced plaques [18]. Therefore, the probable increase in the circulating level of Ang-(1-7) via diminazene would not affect OSS plaque composition. Despite the above speculations the mechanism as to why diminazene did not affect OSSinduced plaques still remains to be elucidated.

Here we reported that diminazene treatment significantly reduced the expression of ICAM-1 and VCAM-1, critical adhesion molecules on endothelial cells favoring atherosclerosis. These results were confirmed by previous studies. For instance, deficiency of ACE2 increased gene expression of VCAM-1 in mouse aorta, while endothelial cells cultured from ACE2 deficiency mice were characterized by increased VCAM-1 gene expression and secretion [24]. A similar effect was observed in cells from wild-type mice treated with the selective ACE2 inhibitor, MLN-4760 [24]. In another study, ACE2 gene transfer inhibited in vitro the monocyte adhesion to endothelial cells, which was associated with a reduction in VCAM-1 and E-selectin protein expression [48]. Moreover, diminazene also reduced IL-1 $1 \beta$, IL-6 and MCP-1, putative mediators of atherogenesis that enhance responsiveness to proinflammatory stimuli. These findings are consistent with previous literature reports [22-24]. Thomas and colleagues [24] found that deficiency of ACE2 in $\mathrm{ApoE}^{-/-}$mice was associated with increased gene expression of several inflammatory cytokines when compared to $\mathrm{ApoE}^{-1-}$ mice, including TNF $\alpha$, IL-6 and CCL2. In another study, ACE2-deficiency enhanced accumulation of macrophages into the lesions which was associated with an increase in proinflammatory markers [23]. Likewise, overexpression of ACE2 leads to a reduction in the expression of intraplaque inflammatory cytokines [22]. Interestingly, diminazene strongly diminished VEGF levels, which is in accordance with previous published reports [49,50]. For example, ACE2 overexpression [50] reduced VEGF expression in a rat model of diabetic nephropathy, while Ang-(1-7) administration produced a similar effect [49]. VEGF is a signal protein with multipotent actions documented in vivo and in vitro; however, its action on plaque vulnerability is not completely understood [51]. In general, it is recognized that VEGF causes immature intraplaque neovascularization highly susceptible to leakage or rupture [52]. Together, these findings suggest that diminazene ameliorates plaque stability parameters by inhibiting the secretion of inflammatory 
cytokines and reducing macrophage infiltration. However, such mechanism still needs to be clarified.

Although one might argue that diminazene may decrease blood pressure and modify the hemodynamic profile at the site of atherosclerosis formation, altering the plaque development and/or composition, previous publications indicated that diminazene does not change blood pressure. It has been documented that diminazene reduced pulmonary hypertension in a rat model without affecting basal systemic blood pressure [27]. Similarly, in a rat model of kidney injury, diminazene produced beneficial outcomes without changing blood pressure [53]. Moreover, diminazene attenuated ischemia-induced cardiac pathophysiology and did affect systolic blood pressure [41]. These results suggest that diminazene-mediated activity is independent on blood pressure change. Nevertheless, as a limitation, the present study did not assess the blood pressure of the studied animals.

\section{Conclusions}

ACE2 is differently expressed in atherosclerotic plaques depending on the local pattern of shear stress forces. Treatment with diminazene, a pharmacological ACE2 activator compound, enhances a stable phenotype of atherosclerotic plaques in which ACE2 is expressed. These plaques, in the LSS region of the carotid and in aortic sinus, usually presented a more vulnerable phenotype, suggesting a selective protective action of diminazene.

\section{Acknowledgments}

This research was funded by the Novartis Consumer Health Foundation (grant to Dr. R. Fraga-Silva); the Swiss National Science Foundation (grant \#310030_156859/1 to Dr. N. Stergiopulos); CNPq and FAPEMIG (grants to Dr. Rafaela F. da Silva).

\section{References}

[1] E. Falk, P.K. Shah, V. Fuster, Coronary plaque disruption, Circulation 92 (3) (1995) 657-671.

[2] A.P. Schroeder, E. Falk, Vulnerable and dangerous coronary plaques, Atherosclerosis 118 Suppl. (1995) S141-S149.

[3] V. Gambillara, C. Chambaz, G. Montorzi, S. Roy, N. Stergiopulos, P. Silacci, Plaqueprone hemodynamics impair endothelial function in pig carotid arteries, Am. J. Physiol. Heart Circ. Physiol. 290 (6) (2006) H2320-H2328.

[4] V. Gambillara, G. Montorzi, C. Haziza-Pigeon, N. Stergiopulos, P. Silacci, Arterial wall response to ex vivo exposure to oscillatory shear stress, J. Vasc. Res. 42 (6) (2005) 535-544.

[5] C. Cheng, D. Tempel, R. van Haperen, A. van der Baan, F. Grosveld, M.J. Daemen, R. Krams, R. de Crom, Atherosclerotic lesion size and vulnerability are determined by patterns of fluid shear stress, Circulation 113 (23) (2006) 2744-2753.

[6] S. Keidar, J. Attias, R. Heinrich, R. Coleman, M. Aviram, Angiotensin II atherogenicity in apolipoprotein $\mathrm{E}$ deficient mice is associated with increased cellular cholesterol biosynthesis, Atherosclerosis 146 (2) (1999) 249-257.

[7] D. Weiss, J.J. Kools, W.R. Taylor, Angiotensin II-induced hypertension accelerates the development of atherosclerosis in apoE-deficient mice, Circulation 103 (3) (2001) 448-454.

[8] A.R. da Silva, R.A. Fraga-Silva, N. Stergiopulos, F. Montecucco, F. Mach, Update on the role of angiotensin in the pathophysiology of coronary atherothrombosis, Eur. J. Clin. Invest. 45 (3) (2015) 274-287.

[9] S. Keidar, R. Heinrich, M. Kaplan, T. Hayek, M. Aviram, Angiotensin II administration to atherosclerotic mice increases macrophage uptake of oxidized LDL: a possible role for interleukin-6, Arterioscler. Thromb. Vasc. Biol. 21 (9) (2001) 1464-1469.

[10] G. Nickenig, D.G. Harrison, The AT(1)-type angiotensin receptor in oxidative stress and atherogenesis: part I: oxidative stress and atherogenesis, Circulation 105 (3) (2002) 393-396.

[11] G.P. Victorino, C.R. Newton, B. Curran, Effect of angiotensin II on microvascular permeability, J. Surg. Res. 104 (2) (2002) 77-81.

[12] W. Ni, S. Kitamoto, M. Ishibashi, M. Usui, S. Inoue, K. Hiasa, Q. Zhao, K. Nishida, A. Takeshita, K. Egashira, Monocyte chemoattractant protein-1 is an essential inflammatory mediator in angiotensin II-induced progression of established atherosclerosis in hypercholesterolemic mice, Arterioscler. Thromb. Vasc. Biol. 24 (3) (2004) 534-539.

[13] R.W. Guo, L.X. Yang, H. Wang, B. Liu, L. Wang, Angiotensin II induces matrix metalloproteinase-9 expression via a nuclear factor-kappaB-dependent pathway in vascular smooth muscle cells, Regul. Pept. 147 (1-3) (2008) 37-44.

[14] Y. Wang, C. Tikellis, M.C. Thomas, J. Golledge, Angiotensin converting enzyme 2 and atherosclerosis, Atherosclerosis 226 (1) (2013) 3-8.
[15] F. Jiang, J. Yang, Y. Zhang, M. Dong, S. Wang, Q. Zhang, F.F. Liu, K. Zhang, C. Zhang, Angiotensin-converting enzyme 2 and angiotensin 1-7: novel therapeutic targets, Nat. Rev. Cardiol. 11 (7) (2014) 413-426.

[16] R.A. Fraga-Silva, D.G. Da Silva, F. Montecucco, F. Mach, N. Stergiopulos, R.F. da Silva, R.A. Santos, The angiotensin-converting enzyme 2/angiotensin-(1-7)/Mas receptor axis: a potential target for treating thrombotic diseases, Thromb. Haemost. 108 (6) (2012) 1089-1096.

[17] S. Tesanovic, A. Vinh, T.A. Gaspari, D. Casley, R.E. Widdop, Vasoprotective and atheroprotective effects of angiotensin (1-7) in apolipoprotein E-deficient mice, Arterioscler. Thromb. Vasc. Biol. 30 (8) (2010) 1606-1613.

[18] R.A. Fraga-Silva, S.O. Savergnini, F. Montecucco, A. Nencioni, I. Caffa, D. Soncini, F.P. Costa-Fraga, F.B. De Sousa, R.D. Sinisterra, L.A. Capettini, et al., Treatment with angiotensin-(1-7) reduces inflammation in carotid atherosclerotic plaques, Thromb. Haemost. 111 (4) (2014) 736-747.

[19] R.A. Fraga-Silva, A.J. Ferreira, R.A. Dos Santos, Opportunities for targeting the angiotensin-converting enzyme 2/angiotensin-(1-7)/mas receptor pathway in hypertension, Curr. Hypertens. Rep. 15 (1) (2013) 31-38.

[20] A. Zulli, L.M. Burrell, R.E. Widdop, M.J. Black, B.F. Buxton, D.L. Hare, Immunolocalization of ACE2 and AT2 receptors in rabbit atherosclerotic plaques, J. Histochem. Cytochem. 54 (2) (2006) 147-150.

[21] J.C. Sluimer, J.M. Gasc, I. Hamming, H. van Goor, A. Michaud, L.H. van den Akker, B. Jutten, J. Cleutjens, A.P. Bijnens, P. Corvol, et al., Angiotensin-converting enzyme 2 (ACE2) expression and activity in human carotid atherosclerotic lesions, J. Pathol. 215 (3) (2008) 273-279.

[22] B. Dong, C. Zhang, J.B. Feng, Y.X. Zhao, S.Y. Li, Y.P. Yang, Q.L. Dong, B.P. Deng, L. Zhu, Q.T. Yu, et al., Overexpression of ACE2 enhances plaque stability in a rabbit model of atherosclerosis, Arterioscler. Thromb. Vasc. Biol. 28 (7) (2008) 1270-1276.

[23] M. Sahara, M. Ikutomi, T. Morita, Y. Minami, T. Nakajima, Y. Hirata, R. Nagai, M. Sata Deletion of angiotensin-converting enzyme 2 promotes the development of atherosclerosis and arterial neointima formation, Cardiovasc. Res. 101 (2) (2014) 236-246.

[24] M.C. Thomas, R.J. Pickering, D. Tsorotes, A. Koitka, K. Sheehy, S. Bernardi, B. Toffoli, T.P. Nguyen-Huu, G.A. Head, Y. Fu, et al., Genetic Ace2 deficiency accentuates vascular inflammation and atherosclerosis in the ApoE knockout mouse, Circ. Res. 107 (7) (2010) 888-897.

[25] S.E. Thatcher, X. Zhang, D.A. Howatt, H. Lu, S.B. Gurley, A. Daugherty, L.A. Cassis Angiotensin-converting enzyme 2 deficiency in whole body or bone marrowderived cells increases atherosclerosis in low-density lipoprotein receptor - / mice, Arterioscler. Thromb. Vasc. Biol. 31 (4) (2011) 758-765.

[26] L.V. Kulemina, D.A. Ostrov, Prediction of off-target effects on angiotensin-converting enzyme 2, J. Biomol. Screen. 16 (8) (2011) 878-885.

[27] V. Shenoy, A. Gjymishka, Y.P. Jarajapu, Y. Qi, A. Afzal, K. Rigatto, A.J. Ferreira, R.A Fraga-Silva, P. Kearns, J.Y. Douglas, et al., Diminazene attenuates pulmonary hypertension and improves angiogenic progenitor cell functions in experimental models, Am. J. Respir. Crit. Care Med. 187 (6) (2013) 648-657.

[28] A. Nencioni, R.F. da Silva, R.A. Fraga-Silva, S. Steffens, M. Fabre, I. Bauer, I. Caffa, M. Magnone, G. Sociali, A. Quercioli, et al., Nicotinamide phosphoribosyltransferase inhibition reduces intraplaque CXCL1 production and associated neutrophil infiltration in atherosclerotic mice, Thromb. Haemost. 111 (2) (2014) 308-322.

[29] V.C. Olivon, R.A. Fraga-Silva, D. Segers, C. Demougeot, A.M. de Oliveira, S.S Savergnini, A. Berthelot, R. de Crom, R. Krams, N. Stergiopulos, et al., Arginase inhibition prevents the low shear stress-induced development of vulnerable atherosclerotic plaques in ApoE - / - mice, Atherosclerosis 227 (2) (2013) 236-243.

[30] E. Maganto-Garcia, M. Tarrio, A.H. Lichtman, et al., Mouse models of atherosclerosis, in: John E. Coligan (Ed.), Current protocols in immunology 2012, pp. 11-23 (Chapter 15:Unit 15 24).

[31] F. Montecucco, V. Di Marzo, R.F. da Silva, N. Vuilleumier, L. Capettini, S. Lenglet, S. Pagano, F. Piscitelli, S. Quintao, M. Bertolotto, et al., The activation of the cannabinoid receptor type 2 reduces neutrophilic protease-mediated vulnerability in atherosclerotic plaques, Eur. Heart J. 33 (7) (2012) 846-856.

[32] D.W. Lambert, M. Yarski, F.J. Warner, P. Thornhill, E.T. Parkin, A.I. Smith, N.M. Hooper, A.J. Turner, Tumor necrosis factor-alpha convertase (ADAM17) mediates regulated ectodomain shedding of the severe-acute respiratory syndromecoronavirus (SARS-CoV) receptor, angiotensin-converting enzyme-2 (ACE2), J. Biol. Chem. 280 (34) (2005) 30113-30119.

[33] A. Mendoza, E. Lazartigues, The compensatory renin-angiotensin system in the central regulation of arterial pressure: new avenues and new challenges, Ther. Adv. Cardiovasc. Dis. 9 (4) (2015) 201-208.

[34] B. Ramkhelawon, J. Vilar, D. Rivas, B. Mees, R. de Crom, A. Tedgui, S. Lehoux, Shear stress regulates angiotensin type 1 receptor expression in endothelial cells, Circ. Res. 105 (9) (2009) 869-875.

[35] M. Cardellini, R. Menghini, E. Martelli, V. Casagrande, A. Marino, S. Rizza, O. Porzio, A Mauriello, A. Solini, A. Ippoliti, et al., TIMP3 is reduced in atherosclerotic plaques from subjects with type 2 diabetes and increased by SirT1, Diabetes 58 (10) (2009) 2396-2401.

[36] J.A. Hernandez Prada, A.J. Ferreira, M.J. Katovich, V. Shenoy, Y. Qi, R.A. Santos, R.K. Castellano, A.J. Lampkins, V. Gubala, D.A. Ostrov, et al., Structure-based identification of small-molecule angiotensin-converting enzyme 2 activators as novel antihypertensive agents, Hypertension 51 (5) (2008) 1312-1317.

[37] R.A. Fraga-Silva, B.S. Sorg, M. Wankhede, C. Dedeugd, J.Y. Jun, M.B. Baker, Y. Li, R.K. Castellano, M.J. Katovich, M.K. Raizada, et al., ACE2 activation promotes antithrombotic activity, Mol. Med. 16 (5-6) (2010) 210-215.

[38] A.J. Ferreira, V. Shenoy, Y. Qi, R.A. Fraga-Silva, R.A. Santos, M.J. Katovich, M.K. Raizada Angiotensin-converting enzyme 2 activation protects against hypertension-induced cardiac fibrosis involving extracellular signal-regulated kinases, Exp. Physiol. 96 (3) (2011) 287-294. 
[39] R.A. Fraga-Silva, F.P. Costa-Fraga, T.M. Murca, P.L. Moraes, A. Martins Lima, R.Q Lautner, C.H. Castro, C.M. Soares, C.L. Borges, A.P. Nadu, et al., Angiotensinconverting enzyme 2 activation improves endothelial function, Hypertension 61 (6) (2013) 1233-1238.

[40] A.S. Peregrine, M. Mamman, Pharmacology of diminazene: a review, Acta Trop. 54 (3-4) (1993) 185-203.

[41] Y. Qi, J. Zhang, C.T. Cole-Jeffrey, V. Shenoy, A. Espejo, M. Hanna, C. Song, C.J. Pepine, M.J. Katovich, M.K. Raizada, Diminazene aceturate enhances angiotensin-converting enzyme 2 activity and attenuates ischemia-induced cardiac pathophysiology, Hypertension 62 (4) (2013) 746-752.

[42] A.P. Mecca, R.W. Regenhardt, T.E. O'Connor, J.P. Joseph, M.K. Raizada, M.J. Katovich, C. Sumners, Cerebroprotection by angiotensin-(1-7) in endothelin-1-induced ischaemic stroke, Exp. Physiol. 96 (10) (2011) 1084-1096.

[43] R.A. Fraga-Silva, F.P. Costa-Fraga, F. Montecucco, M. Sturny, Y. Faye, F. Mach, G. Pelli, V. Shenoy, R.F. da Silva, M.K. Raizada, et al. Diminazene protects corpus cavernosum against hypercholesterolemia-induced injury, J. Sex. Med. 12 (2) (2015) 289-302.

[44] G. Foureaux, J.C. Nogueira, B.S. Nogueira, G.O. Fulgencio, G.B. Menezes, S.O Fernandes, V.N. Cardoso, R.S. Fernandes, G.P. Oliveira, J.R. Franca, et al., Antiglaucomatous effects of the activation of intrinsic angiotensin-converting enzyme 2, Invest. Ophthalmol. Vis. Sci. 54 (6) (2013) 4296-4306.

[45] S.E. Thatcher, X. Zhang, D.A. Howatt, F. Yiannikouris, S.B. Gurley, T. Ennis, J.A. Curci, A. Daugherty, L.A. Cassis, Angiotensin-converting enzyme 2 decreases formation and severity of angiotensin II-induced abdominal aortic aneurysms, Arterioscler. Thromb. Vasc. Biol. 34 (12) (2014) 2617-2623.

[46] Y. Zhang, J. Liu, J.Y. Luo, X.Y. Tian, W.S. Cheang, J. Xu, C.W. Lau, L. Wang, W.T. Wong C.M. Wong, et al., Upregulation of angiotensin (1-7)-mediated signaling preserves endothelial function through reducing oxidative stress in diabetes, Antioxid. Redox Signal. (2015) [Epub ahead of print].
[47] F. Lovren, Y. Pan, A. Quan, H. Teoh, G. Wang P.C. Shukla, K. S. Levitt, G.Y. Oudit, M. Al-Omran, D.J. Stewart, et al., Angiotensin converting enzyme-2 confers endothelial protection and attenuates atherosclerosis, Am. J. Physiol. Heart Circ. Physiol. 295 (4) (2008) H1377-H1384

[48] Y.H. Zhang, Y.H. Zhang, X.F. Dong, Q.Q. Hao, X.M. Zhou, Q.T. Yu, S.Y. Li, X. Chen, A.F. Tengbeh, B. Dong, et al., ACE2 and Ang-(1-7) protect endothelial cell function and prevent early atherosclerosis by inhibiting inflammatory response, Inflamm. Res. 64 (3-4) (2015) 253-260 (et al.).

[49] K. Zhang, X. Meng, D. Li, J. Yang, J. Kong, P. Hao, T. Guo, M. Zhang, Y. Zhang, C. Zhang, Angiotensin(1-7) attenuates the progression of streptozotocin-induced diabetic renal injury better than angiotensin receptor blockade, Kidney Int. 87 (2) (2015) 359-369.

[50] C.X. Liu, Q. Hu, Y. Wang, W. Zhang, Z.Y. Ma, J.B. Feng, R. Wang, X.P. Wang, B. Dong, F. Gao, et al., Angiotensin-converting enzyme (ACE) 2 overexpression ameliorates glomerular injury in a rat model of diabetic nephropathy: a comparison with ACE inhibition, Mol. Med. 17 (1-2) (2011) 59-69.

[51] P.R. Moreno, M. Purushothaman, K.R. Purushothaman, Plaque neovascularization: defense mechanisms, betrayal, or a war in progress, Ann. N. Y. Acad. Sci. 1254 (2012) 7-17.

[52] J.B. Michel, J.L. Martin-Ventura, A. Nicoletti, B. Ho-Tin-Noe, Pathology of human plaque vulnerability: mechanisms and consequences of intraplaque haemorrhages, Atherosclerosis 234 (2) (2014) 311-319.

[53] E. Velkoska, S.K. Patel, K. Griggs, R.J. Pickering, C. Tikellis, L.M. Burrell, Short-term treatment with diminazene aceturate ameliorates the reduction in kidney ACE2 activity in rats with subtotal nephrectomy, PLoS One 10 (3) (2015), e0118758. 